\title{
Endüstriyel Pazarlarda İlişki Kalitesinin Müşteri Sadakatine Etkisi
}

\author{
Keti VENTURA* Arıç KÜÇÜK **
}

\begin{abstract}
$\ddot{O} Z$
Günümüzde yoğun rekabetin getirdiği pazar dinamikleri sürekli değişmekte ve işletmeler bu değişim ve gelişmeye ayak uydurabilmek ve rekabette bir adım önde olabilmek için geleneksel fiyat politikalarının yanı sıra, müşteri merkezli ve uzun dönemli ilişki kalitesini arttırmaya yönelik politikalar izlemek durumunda kalmaktadirlar. Bu durum özellikle de fiyat rekabetinin belirleyici olduğu endüstriyel pazarlarda daha da önemli hale gelmektedir. İnşaat sektörü bu anlamda rekabetin en yoğun yaşandığ sektörlerden biridir. Yapı denetim sisteminin günden güne oturmaya başlaması ve sektörde standartların oluşturulmastyla özellikle hazır beton endüstrisindeki işletme sayısı da ciddi şekilde artmaktadır. Bu çerçevede, fiyat politikaları tek başına rekabette yeterli olmamakta, verilen hizmetin kalitesi ve müşteri ilişkilerini geliştirmek rekabet avantajı yaratan en önemli unsurlar haline gelmektedir. Bu doğrultuda çalışmanın amacı, Batıbeton Beton San. A.Ş.'nin müşsterilerine yönelik ilişkilerindeki kalitesi algılamalarının, müşteri sadakati üzerindeki etkisini ölçmektir. Tanımlayıcı araştırma niteliğinde tasarlanan çalışmada, veri toplama yöntemi olarak anket tekniği kullanılmıştır. İlişki kalitesi boyutlarından bağlllık ve atmosfer müşteri sadakatini arttıran en önemli boyutlar olarak algılanırken, iletişim düzeyi de kısmi moderatör olarak değerlendirilmiştir.
\end{abstract}

Anahtar Kelimeler: İlişki kalitesi, müşteri sadakati, hazır beton sektörü

JEL Sinıflandırması: M31, M30, M10

\section{The Effect of Relationship Quality in B2B on Customer Loyalty}

\begin{abstract}
Today, as market dynamics are constantly changing due to the intensive competition, using the pricing policies as a tool for competition in order to keep up with the change and improvements are not solely adequate. Businesses have to follow customer based policies to improve long term relationship quality. This is especially important in industrial markets where price competition is decisive. The construction sector is one of the sectors where competition is most intense. With the construction supervision system starting to settle and the standards in the sector being established, the number of enterprises in the ready-mixed concrete industry is also seriously increasing. In this framework, price policies are not solely enough for competition, improving quality of service and customer relations are becoming the most important elements that create a competitive advantage. Within this context, the aim of the study is to measure the impact of customer perceptions of relationship quality on customer loyalty of Batıbeton Beton San. A.Ş. The study is designed as a descriptive research and survey technique was used as a data collection method. While commitment and atmosphere from the relationship quality dimensions are perceived as the most important dimensions that increase customer loyalty, the level of communication is evaluated as a partial moderator.
\end{abstract}

Keywords: Relationship quality, customer loyalty, concrete industry

JEL Classification: M31, M30, M10

* Doç.Dr. Ege Üniversitesi İ̈BF,İşletme Bölümü. keti.ventura@ ege.edu.tr
${ }^{* *}$ Batıbeton Beton San. A.Ş.,Manisa Tesis Şefi,arinckucuk@baticim.com.tr

(Makale Gönderim Tarihi: 23.08.2016 / Yayına Kabul Tarihi: 15.02.2017)

Doi Number: 10.18657/yonveek.307524 


\section{GíRIŞ}

2000 y1lı öncesinde, hazır beton sanayinde müşterinin yarattı̆g 1 talebi karşılayacak işletme sayısının azlığı, talebin artışına paralel arzı yaratacak işletmelerin aynı derecede artmaması, sektör genelinde pazarlama anlayışının oluşmasını engellemiş, işletmelerin üretim odaklı politika ve stratejiler üzerinden faaliyetlerini sürdürdükleri görülmüştür. 2000 yılı sonrasında ise sektöre giren işletme sayısının artması, halihazırda faaliyet gösteren işletmeleri de ciddi bir pazarlama faaliyeti içerisine girmeye zorlamıştır. Günümüzde endüstriyel pazarlarda, pazarlama anlayışının fiyat vermekten ibaret olmadığı, rekabet avantajı sağlamanın en önemli yollarından birinin müşteri ilişkilerinde kalitenin sağlanması gerektiği görülmektedir. Bu kapsamda ilk aşamada endüstriyel pazarlarda ilişki kalitesinin önemi ve boyutları üzerinde durulmuş, daha sonra müşteri sadakati ve ilişki kalitesi boyutlarının müşteri sadakati üzerindeki etkilerine ilişkin literatür çalışması yapılmışıtır. Son olarak da alan araştırması bulgularına yer verilmiştir.

\section{I.ENDÜSTRIYEL PAZARLARDA İLIŞKI KALITESI}

Rekabet çevresinin oldukça yoğun olduğu günümüzde, işletmeler sadece ürün/hizmette kaliteyi sağlamak ile değil, müşterilerini uzun dönemli elde tutmak ve karlı bir ilişki ortamı yaratabilme gücü temelinde rekabet etmektedirler. Endüstriyel pazarlarda işletmeler arasında kurulan sağlam ilişkiler, bulundukları sektörlerde işletmelere rekabet avantajı sağladığı gibi, aynı zamanda geleceğe yönelik başarılı işlerin yapılmasına da imkan tanımaktadır (Panayides, 2002:151; Ulaga, 2003:679). Özellikle rekabetin yoğun olduğu endüstrilerde işletmeler arasındaki ilişkilerin sürekliliği, ürün kalitesinin beklenen düzeyde olmasının yanı sıra işletmeler arası kurulmuş sağlam ilişkilerin varlığına dayanmaktadır. Bu durum özellikle endüstriyel pazarlarda, ilişkisel pazarlama kavramının önemini daha da arttırmaktadır. İlişkisel pazarlamanın temel hedefi, müşteri sadakatini arttırarak işletme ve müşteri arasında güçlü ilişkiler kurmaktır (Peng ve Wang, 2006:26). Özellikle son yıllarda ilişkisel pazarlama iş ilişkisine konu olan taraflar arasındaki ilişkinin kalitesine odaklanmıştır (Huntley, 2006:703). İlişki kalitesi, ilişkisel pazarlamanın önemli bir destekçisi olup (Gümmesson, 2002:38) başarılı iş ilişkilerinde ilişki kalitesinin önemli bir ölçütüdür (Nyaga ve Whipple, 2011:346; Liu vd., 2010:4).

İlişki kalitesi, özellikle ürünlerin benzer kalitede olduğu endüstriyel pazarlarda daha da önemli hale gelmektedir. Literatürde ilişki kalitesinin tanımı ile belirleyicileri üzerinde ortak bir görüş geliştirilememiştir. Bunun temel nedeni araştırmacıların bu kavramın içeriğine daha sezgisel yaklaşmaları (HennigThurau,2002:234) ve gerek tüketici gerekse endüstriyel pazarlarda ilişkilerin çok çeşitli olmasıdır (Woo ve Ennew: 2004:1254). Ancak Woo ve Ennew (2004), bu konuda gelişmenin sağlanabilmesi için alıcı ve satıcı arasındaki ilişkinin genel olarak değerlendirilmesi gerektiğini ve asıl odak noktasının söz konusu ilişkiyi oluşturan boyutlar olduğunu ifade etmiştir. Taraflar arasındaki ilişkinin kaliteli olarak algılanması, müşteri memnuniyetini, sadakatini, olumlu ağızdan ağıza iletişimi, taraflar arası iş ilişkilerinin sürdürülebilir olmasını sağlamaktadır. İlişkinin kaliteli olarak algılanması, tarafların zaman içinde ilişkiye olan 
bağl111klarını arttıracak ve ilişkiye katkılarını arttırmalarına yönelik onları motive edecektir (Rauyruen ve Miller, 2007:28).

Literatürde ilişki kalitesi hem tüketim pazarı hem de endüstriyel pazarlar bağlamında çalışmalara konu olmuştur. Satış personeline olan güven, satış personelinden memnuniyet düzeyi ve ilişkiye olan bağl1lık literatürde oldukça sık kullanılan (Athanasopoulou, 2009; Holmlund, 2008; Woo ve Ennew, 2004) tüketici-temelli boyutlar olmasına rağmen, endüstriyel pazarlarda işletmeler arasındaki ilişki kalitesini ölçmek amacıyla da kullanılmıştır. Endüstriyel işletmeler arasında ilişki kalitesini, Huntley (2006), ürün kalitesi (teknik boyut), hizmet kalitesi (sosyal boyut), fiyat (ekonomik boyut), işbirliği atmosferi ve bütünsel global memnuniyet boyutlarıyla; Leonidou vd. (2006), uyumlaştırma, bağl1lık, iletişim, işbirliği, memnuniyet, güven ve anlayış boyutlarıyla; Cater ve Cater (2010), uyumlaştırma, bilgi transferi, güven ve işbirliği boyutlarıyla, Nyaga (2011) güven, bağlılık, memnuniyet ve ilişkiye özgü yatırımlar boyutlarıyla; Song vd. (2012), işbirliği, uyumlaştırma ve atmosfer boyutlarıyla; Moliner vd. (2013), güven, bağlılık ve memnuniyet boyutlarıyla; Madupalli vd. (2014), güven, bağl1lık ve iletişim kalitesi boyutlarıyla ele almıştır.

Bunun yanı sıra iletişim düzeyi ilişkinin tarafları arasındaki ilişki sürecinin en önemli elemanlarından biridir (Guenzi vd.,2007:122). Özellikle endüstriyel pazarlarda iletişimin temel hedefi, tarafların eğilimlerinin ve yetkinliklerinin karşılıklı olarak anlaşıldığından emin olunmasıdır (Mohr ve Spekman, 1994:138). İletişim yapısı işletmeler arasında resmi ve resmi olmayan bilginin paylaşılmasını ve bunun zamanında ve anlaşılabilir olmasını gerektirmektedir. Kaliteli bir iletişim, ilişki çıtılarını arttırırken, güçlü ve uzun dönemli bir ilişkinin oluşturulmasında da önemli bir belirleyicidir (Madupalli vd.,2014:161).

\section{II. İLIŞKI KALITESİNIN BOYUTLARI}

Yukarıda sözü edildiği gibi ilişki kalitesi literatürde çok farklı boyutları ile ele alınmıştır. Bu çalışmanın endüstriyel işletmelere yönelik olması ve uygulamada ele alınan hazır beton sektöründe taraflar arası ilişkilerin ve işin doğası gereği ilişki kalitesi; güven, bağl1lık, uyarlama, atmosfer ve memnuniyet boyutlarıyla ele alınmıştır.

Güven: Güven, ilişki kalitesi literatüründe birçok yazar tarafindan kullanılan bir boyut olmakla birlikte (ör. Leonidou vd.,2006), Cater ve Cater, 2010, Nyaga, 2011, Moliner vd. 2013, Madupalli vd. 2014) taraflar arasındaki iş ilişkisinin başarısını etkileyen önemli bir değişkendir (Sahay, 2003:553). Güven, müşterinin, satıcının kendi yararı ve kendisine olumlu çıtılar yaratma inancında olmasıyla yakından ilişkilidir (Ganeson, 1994:3). İşletmelerin müşterileriyle ya da tedarik zincirinin diğer elemanlarıyla olan ilişkilerinde verilen sözlerin karşı1lıklı olarak tutulması, kaliteli bir ilişkinin kurulması ve geliştirilmesi için oldukça önemlidir.

Bağl1lık: Gounaris (2005:127), bağlılığı, süreklilik sağlamak amacıyla bir ilişkiye kaynak yatırımı konusundaki isteklilik olarak ifade etmiştir. Bağlılık, başarılı ilişkilerin en önemli belirleyicilerinden olmakla birlikte (Morgan ve Hunt, 
1994; Athanasopoulou, 2009; Holmlund, 2008; Woo ve Ennew, 2004; Leonidou vd., 2006; Cater ve Cater, 2010; Nyaga, 2011; Moliner vd., 2013; Madupalli vd.,2014) bir iş ilişkisinde bağlılık, iş ortaklarıyla sürekli bir ilişki oluşturmaya yönelik tutum geliştirilmesini sağlamaktadır. Bağlılığın geliştirilebilmesi için alıcının, satıcıya ilişkin hiçbir olumsuz eğiliminin olmayacağına inanması ve alıcının, mevcut ya da geçmiş deneyimlerinin, gelecekteki eğilimlerinin güçlü bir belirleyicisi olduğuna inanması gerekmektedir (Sindhav ve Lusch ,2008:285).

Uyarlama: Uyarlama, bir işletme tarafindan bir başka işletmenin belirli ihtiyaçlarını karşılamak üzere kişi, grup ya da işletme temelinde yapılan davranışsal ya da yapısal değişiklikler olup (Brennan ve Turnbull, 1999:482), taraflar arası ilişkinin etkinliğini ve sağlamlığını arttırmak için gerçekleştirilmektedir ( $\mathrm{Su} \mathrm{vd.,}$ 2008:265). Özellikle işletmeler arası uzun süreli ilişkilerin sağlanmasında uyarlama önemli bir değişken olarak kullanılmaktadır (Leonidou vd.,2006; Cater ve Cater, 2010; Song vd.,2012).

Atmosfer: Atmosfer, genel olarak iş ilişkisinin içinde bulunduğu ortamı ifade etmektedir. Özellikle endüstriyel pazarlarda iş ilişkisinde bulunulan işletmelerin sadece satıcı ya da bir iş ortağı olarak görülmesi olumlu bir atmosfer yaratılmasını sağlayacaktır. Karşı tarafın bir iş ortağı olarak görülmesi, karşılıklı hedefleri başarmaya odaklı bir ilişkinin kurulmasına yardımcı olacaktır (Huntley, 2006:704). Alıcı ve satıcı arasındaki yüksek ilişki kalitesi, tarafların birbirlerinin ihtiyaçlarını ve tercihlerini anladığı uyumlu bir atmosferle mümkün olabilmektedir (Su, vd, 2008:266). Bu şekilde yaratılan bir atmosfer, alıcının ilişkinin değeri ile ilgili olan algısını da arttırmaktadır (Song, 2012:295).

Memnuniyet: Müşteri memnuniyeti, müşterilerin ürün ya hizmetin satın alımından sonra yaşadığı deneyime dayalı olarak oluşan genel bir tutumdur (Fornell, 1992:7). Bu tutum, iş ortağının algılanan performansının endüstrideki standartlara göre beklendiği gibi ya da beklentiyi aştığı durumlarda görülmektedir (Spreng vd.,1996:17). Tarafların karş1lıklı olarak iş ilişkisinden memnuniyet duymaları, uzun dönemli ve derin bir ilişki yapısının oluşmasını sağlamaktadır (Eriksson ve Vaghult, 2000:365). Memnuniyet düzeyi arttıkça ilişki kalitesi de artmaktadır (Huntley, 2006; Leonidou vd.,2006; Nyaga, 2011;Moliner vd., 2013).

\section{ENDÜSTRIYYL PAZARLARDA MÜŞTERİ SADAKATİ}

Günümüzde yaşanan yoğun rekabet, müşteri edinme maliyetinin artmasına ve özellikle belirli bir doygunluğa ulaşmış olan pazarlarda, satıcıları yeni müşteri bulmaktansa mevcut müşterileri sadık müşteri haline getirmeye zorlamaktadır. Müşteri sadakati yaratmanın en önemli yollarından biri şüphesiz müşteri memnuniyetini sağlamaktır (Veloutsou vd., 2004:115). Literatürde müşteri sadakati üzerinde çeşitli ve çok boyutlu tanımlar bulunmaktadır. Bazı yazarlar (Griffin, 1996; Bowen ve Shoemaker 2003; Chang ve Chen, 2007) müşteri sadakatini davranışsal yönüyle açıklarken (belirli bir zaman diliminde tekrar satın alma, satın alma olasılı̆̆ yazarlar da (Boonlertvanich, 2011; Kumar ve Shah, 2004: 318), tutumsal yönüyle (alternatifler arasındaki tercihler, tekrar satın alma eğilimi, psikolojik bağl1lık, arkadaşlarına ya da meslektaşlarına tavsiye etme ihtimali vb.) açıklamaktadır. 
Literatürde her iki boyutu ele alan ya da daha fazla boyutu birleştiren çalışmalar da bulunmaktadır (ör: Rauyruen ve Miller, 2007).

Endüstriyel pazarlarda taraflar arasındaki iş ilişkisinin kalitesi müşteri sadakatinin en önemli belirleyicilerinden biri olarak karşımıza çıkmaktadır (Roberts vd, 2003:175; Rauyruen ve Miller, 2007:22). Özellikle de günümüzde rekabetin tedarik zinciri bünyesinde başlaması, işletmeleri diğer ağ yapılarıyla rekabet etme durumunda bırakmaktadır (Arslan, 2012). Dolayısıyla, tedarikçiler ya da diğer iş ortaklarıyla kurulan ilişkinin kalitesi daha da önemli hale gelmektedir. Değer zincirindeki tüm aktörlerin, özellikle de kurumsal müşterilerin, karşl1ıklı olarak istek, tercih ve beklentilerinin karşılandığ1, koordineli ve işbirliği halinde çalışılan uyumlu bir çalışma kültürünün yaratıldığ 1 ve en önemlisi de tarafların birbirlerine değer yarattı̆g 1 bir çalışma sisteminin oluşturulması, ilişki kalitesini arttıracaktır. Russo vd. (2015:1) müşteriye özel çözümler sunmanın hatta her müşteriye özel reçete hazırlamanın sağlam, güçlü ve derinliği olan uzun süreli ilişkiler ile müşteri sadakatini arttırmanın mümkün olabileceğini ifade etmiştir. Özellikle endüstriyel pazarlarda taraflar mevcut iş ilişkisini verimli ve memnuniyet verici bulduğu durumlarda, bu ilişkiyi değiştirme ihtiyac1 hissetmeyeceklerdir (Leverin ve Liljander, 2006:12).

Günümüzde ürün, kalite ve fiyat gibi konulardan çok rekabet, işletmeler arasında kurulan ağlar ve bu ağlara dayalı olarak oluşturulan ilişkilerin kalitesi temelinde sürdürülmektedir. Yukarıda ayrıntılarıyla ifade edilen ilişki kalitesi, farklı boyutları itibariyle ele alınmış olsa da, müşteri sadakatini arttırdığı ortaya konmuştur (Henning-Thurau vd., 2002; Lin ve Ding, 2006; Rauyruen ve Miller, 2007). Bu ilişkinin başarılı ve sürdürülebilir bir ilişki olabilmesi için Müşteri İlişkileri Yönetimi (Customer Relationship Management-CRM) yazılımlarıyla desteklenmesi gerekmektedir (Hunt vd., 2006:80). Bu teknolojiler, her müşteriye özgü verilerin saklanmasına ve onlara özgü strateji geliştirilmesine olanak tanıyarak daha güçlü ilişkilerin kurulmasını sağlamaktadır.

\section{ILLIŞKI KALITESININ MÜŞTERI SADAKATINE ETKISİ: BATIBETON EGE BÖLGESİ ALÂN ARAŞTIRMASI}

Çalışmanın bu bölümünde, Batıbeton Beton San. A.Ş'de yapılmış olan alan çalışmasının amaç, metodoloji ve bulgularına yer verilmektedir.

Hazır Beton sektörü, inşaat sektörünün en temel kollarından birini oluşturmaktadır. Türkiye'de 2013 yılında 102 milyon metreküp beton üretimi gerçekleşmiştir. 2014 yılında ise bu rakamın yüzde 5 büyüme ile 107 milyon metreküpe ulaşmışırı. Önümüzdeki yıllarda inşaat sektörünün canlanmasına paralel olarak, Hazır Beton sektörünün de canlanacağını öngörülmektedir (THBB, 2015:14). Batıbeton Beton San. A.Ş. 01.01.2016 öncesinde Batıçim Batı Anadolu Çimento Sanayii A.Ş'ye bağlı olarak faaliyet göstermektedir. Batıçim 1966 y1lında, yüzde 100 Türk sermayesi ile kurulduktan sonra ülkemiz çimento ihtiyacının önemli bir kısmını karşılamakla kalmamış, uluslararası pazarlarda tanınan bir kuruluş olmuştur. Batıçim, 1986 yılında inşaat sektörünün artan beton ihtiyacının karşılanması ve hazır beton bilincinin yayılması amacıyla Batıbeton markasını 
sektörün hizmetine sunmuştur. 1986 yılında İzmir Bornova 'da hazır beton üretimine başlanmış ve halen İzmir, Manisa ve Aydın ili ve ilçelerinde 15 hazır beton tesisi, 18 hazır beton santralı ile $2000 \mathrm{~m}^{3} /$ saat'lik kapasite ile üretim yapabilmektedir. Batıbeton markası, 01.01.2016 tarihinden itibaren Batıbeton Beton San. A.Ş. tüzel kişiliği altında faaliyetlerini sürdürmektedir.

\section{A. Araştırmanın Amacı ve Kapsamı}

$\mathrm{Bu}$ çalışmada amaç, Batıbeton Beton San. A.Ş.'nin bayileri ve diğer müşterileri ile olan ilişkilerinin kalite boyutlarını ortaya koymak ve bu boyutların müşteri sadakati üzerindeki etkisini ölçmektir. Batıbeton grubunun seçilmesinin nedeni, gerek ürün çeşitliliği anlamında gerekse müşterilerle ilişkiler anlamında çimento grubuna göre daha kapsamlı pazarlama faaliyetlerini yürütmesidir. $\mathrm{Bu}$ kapsamda, ilk etapta beton tesisi yetkilileri ile görüşülerek Batıbeton bayileri ve bayi müşterileri ile olan ilişki yapısı değerlendirilmiştir. Elde edilen bulgular doğrultusunda ilişki kalitesi ile müşteri sadakati boyutları, beton sanayine göre uyarlanarak alan çalışması gerçekleştirilmiştir.

\section{B. Araştırmanın Metodolojisi}

Alan araştırması, tanımlayıcı bir araştırma şeklinde gerçekleştirilmiş, çalışmada birinci elden toplanan veriler kullanılmıştır. Veri toplama yöntemi olarak da anket tekniği kullanılmıştır. Tanımlayıcı araştırma, olguların, nesnelerin, insanların, grupların veya örgütlerin özelliklerini ortaya çıkararak bir durumun ya da olgunun ayrıntılarla anlatıldı̆̆ araştırmalardır (Gürbüz ve Şahin, 2015:99).

$\mathrm{Bu}$ çalışmanın tanımlayıcı bir araştırma olmasının nedeni, ilişki kalitesi boyutlarının müşteri sadakati üzerindeki etkilerinin ortaya konduğu ve bu duruma ilişin bulguların açıklandığı bir araştırma olmasıdır. Çalışmanın sonunda elde edilen veriler, SPSS 22.0 paket programı kullanılarak analiz edilmiştir.

\section{C. Örneklem Çerçevesi, Veri Toplama ve Kısıtlar}

Araştırmada veri toplama yöntemi olarak anket tekniği kullanılmıştır. Anket tekniği, birinci elden veri toplamada en çok başvurulan yöntemdir. Örneklem çerçevesini, Batıbeton Beton Sanayi A.Ş.'nin Ege Bölgesi'nde yer alan tesisleri ve bayileri aracılığıyla Manisa, İzmir ve Denizli'de fiili olarak inşaat yapan müteahhitlik ve inşaat üst düzey yönetici ya da proje müdürleri oluşturmaktadır. Son bir y1lda aktif olarak faaliyette bulunan 655 müşteriye anket gönderilmiştir, ancak işletmelerin anket cevaplama konusundaki isteksizlikleri nedeniyle toplam 61 anketin geri dönüşü sağlanmıştır. Bu durum araştırmanın en önemli kısıtını oluşturmaktadır.

Anket formu üç bölümden oluşmaktadır. İlk bölümde firmalar ile ilgili genel bilgiler yer almaktadır. İkinci bölümde firmaların Batıbeton ile sürdürülen ilişkilerinin kalitesinin çeşitli boyutlar temelinde değerlendirilmesine olanak sağlayan sorular bulunmaktadır. Son bölümde de işletmelerin sadakat düzeylerini ölçen sorulara yer verilmiştir.

\section{Araştırmada Kullanılan Ölçekler}

Anket soruları kapsamında ilişki kalitesi, literatür kısmında da ayrıntılarıyla belirtildiği gibi güven, bağlılık, uyarlama, atmosfer ve memnuniyet boyutlarıyla ölçülmüsstür. Müşteri sadakati bağımlı değişken olarak yer almaktadır. 
İlişki kalitesi boyutları beton tesisi yetkilileri ile görüşülerek literatürde belirlenen boyutlar çerçevesinde, sektörün içinde bulunduğu ilişki dinamikleri göz önünde bulundurularak belirlenmiştir. Değişkenlerin ölçümlenmesinde kullanılan boyutlar, ölçekleri ve ifadelerin oluşturulmasında yararlanılan çalışmalar Tablo 1'de gösterilmektedir.

Tablo 1: Değişkenlerin Ölçülmesinde Yararlanılan Çalıșmalar

\begin{tabular}{|c|c|}
\hline DEĞİŞKENLER & YARARLANILAN ÖLÇEK \\
\hline İlişki Kalitesi & $\begin{array}{l}\text { 5’li Likert Ölçeği } \\
\text { Kesinlikle katılmıyorum (1)-Kesinlikle katılıyorum (5) } \\
\qquad 19 \text { ifadeden oluşmaktadır. }\end{array}$ \\
\hline Güven & $\begin{array}{l}\text { Cater ve Cater (2010); Huntley (2006); Mitręga ve Katrichis (2010); Nyaga } \\
\text { (2011); Raza ve Rehman (2012); Gil-Saura, Frasquet-Deltoro,Cervera-Taulet } \\
\text { (2009) }\end{array}$ \\
\hline Bağlilık & $\begin{array}{l}\text { Huntley (2006); Nyaga (2011); Gil-Saura, Frasquet-Deltoro,Cervera-Taulet } \\
\text { (2009) }\end{array}$ \\
\hline Uyarlama & Cater ve Cater (2010); Woo ve Ennew (2004); Song vd. (2012) \\
\hline Atmosfer & Song vd. (2012);Nyaga (2011); Raza ve Rehman (2012) \\
\hline Memnuniyet & Nyaga (2011); Raza ve Rehman (2012) \\
\hline Müşteri Sadakati & $\begin{array}{l}\text { 5'li Likert Ölçeği } \\
\text { Kesinlikle katılmıyorum (1)-Kesinlikle katılıyorum (5) } \\
4 \text { ifadeden oluşmaktadır. } \\
\text { Cater ve Cater (2010); Raza ve Rehman (2012); Gil-Saura, Frasquet- } \\
\text { Deltoro,Cervera-Taulet (2009) }\end{array}$ \\
\hline Firma Özellikleri & \\
\hline Büyüklüğü & Çalışan Sayısı \\
\hline Mevcut Konum & Müteahhit-Yapı Elemanları-Diğer \\
\hline İnşaat Hacmi & (son 5 yılda) yılllk ortalama yapılan inşaat sayısı \\
\hline Satış Hacmi & Proje başına ortalama satış süresi \\
\hline Fiili İnşaat Sayısı & Fiili olarak inşaat yapılan yıl sayısı \\
\hline
\end{tabular}

Hazırlanan anket beton sanayinde faaliyet gösteren yöneticilerin görüşleri alınarak revize edilmiş ve son hali verilmiştir. Alan çalışmasından önce bu konuda uzman kişilerin görüşlerinin alınmasının nedeni, sektör yetkililerinin müşterilerle olan ilişkilerin doğasına hakim olması ve soru formunun anlaşılabilirliğinin sağlanmasıdır. Alan çalışması, Ekim-Aralık 2016 tarihleri arasında gerçekleştirilmiştir. Anketler karşılıklı görüşme şeklinde ve bazen istenildiği durumlarda da e-posta yoluyla gönderilerek cevaplandırılmıştır. şekildedir:

$\mathrm{Bu}$ doğrultuda araştırmaya kapsamında oluşturulan hipotezler şu

$\mathrm{H}_{1}=$ İlişkide güven arttıkça müşteri sadakati artmaktadır.

$\mathrm{H}_{2}=$ İliş̧kiye olan bağl1lık arttıkça müşteri sadakati artmaktadır.

$\mathrm{H}_{3}=$ Müşteri isteklerine uygun olarak yapılan ürün/hizmet uyarlamaları müşteri sadakatini arttırmaktadır.

$\mathrm{H}_{4}=$ Müşteriler ile yaratılan atmosfer müşteri sadakatini arttırmaktadır.

$\mathrm{H}_{5}=$ Illişkiden duyulan memnuniyet düzeyi müşteri sadakatini arttırmaktadır.

\section{E. Araştırmanın Bulguları}

Araştırma kapsamında değerlendirilen işletmelerin yüzde 83,6's1 kendilerini konut, yüzde 16,4 'ü ise sanayi işletmesi olarak tanımlamaktadır. 
Katılımeı işletmeler, eşit oranlarda Manisa, İzmir ve Denizli illerinde faaliyet göstermekte olup, katılımcıların yüzde 77'si 10'dan az personel çalıştıran, yüzde 13,1'i de 10-24 arası personel çalıştıran işletmelerdir. Bunların büyük çoğunluğu (yüzde 88,5) konut müteahhitlerinde olmakla beraber, kalan yüzde 11,5'i büyük sanayi projeleri yapan işletmelerdir. Katılımcıların satış hacimleri incelendiğinde Manisa bölgesinde yüzde 76 ile 10-12 ay arası satış sonlandırması gözlenirken, İzmir bölgesinde bu oran yüzde 64 ile 1 y1l ve üzeri, Denizli bölgesinde yüzde 68 ile 1 yıl üzeri olarak gerçekleşmektedir.

Tablo 2: Araştırma Kapsamında Değerlendirilen İșletmelerin Genel Profili

\begin{tabular}{|c|c|c|c|c|c|}
\hline Bulunduğu İl & $\mathrm{N}$ & $\begin{array}{l}\text { Geçerli } \\
\text { Yüzde }\end{array}$ & Faaliyet Alanı & $\mathrm{N}$ & $\begin{array}{l}\text { Valid } \\
\text { Percent }\end{array}$ \\
\hline Manisa & 21 & 34,4 & Konut & 51 & 83,6 \\
\hline İzmir & 20 & 32,8 & Sanayi & 10 & 16,4 \\
\hline Denizli & 20 & 32,8 & Toplam & 61 & 100 \\
\hline Toplam & 61 & 100 & & & \\
\hline \multicolumn{3}{|l|}{\begin{tabular}{|l|} 
Çalışan Sayısı \\
\end{tabular}} & \multicolumn{3}{|c|}{ Firmanın Konumu } \\
\hline \begin{tabular}{|l|}
$10 ' d a n ~ a z$ \\
\end{tabular} & 47 & 77 & Mütahhit & 54 & 88,5 \\
\hline $10-24$ & 8 & 13,1 & Yapı elemanı & 7 & 11,5 \\
\hline $25-49$ & 6 & 9,8 & Toplam & 61 & 100 \\
\hline 50240 & - & - & & & \\
\hline $50-249$ & $e_{61}^{-}$ & - & & & \\
\hline $\begin{array}{l}250+ \\
\text { Toplam }\end{array}$ & & & & & \\
\hline \multicolumn{3}{|l|}{ İnşaat Hacmi } & \multicolumn{3}{|l|}{ Satıș Hacmi } \\
\hline $0-5$ adet & 52 & 85,2 & $0-3$ ay & 1 & 1,6 \\
\hline 6-10 adet & 9 & 14,8 & $4-6$ ay & 3 & 4,9 \\
\hline $11-15$ adet & - & - & $7-9$ ay & - & - \\
\hline $16-20$ adet & - & - & $10-12$ ay & 20 & 32,8 \\
\hline Toplam & 61 & 100 & 1 y1l üstü & 37 & 60,7 \\
\hline & & & Toplam & 61 & 100 \\
\hline \multicolumn{6}{|c|}{\begin{tabular}{|l} 
Fiili İnşaat Sayısı \\
\end{tabular}} \\
\hline 5 yil altı & 1 & 1,6 & & & \\
\hline 5-9 y1l & 7 & 11,5 & & & \\
\hline $10-14$ y1l & 40 & 65,6 & & & \\
\hline $15-19$ y1l & 8 & 13,1 & & & \\
\hline 20 yıl ve üstü & 5 & $\begin{array}{l}8,2 \\
100\end{array}$ & & & \\
\hline
\end{tabular}

Araştırma kapsamında işletmelerin Batıbeton Beton San. A.Ş. ile olan ilişki kalitelerini ölçmek amacıyla, Tablo 1'de de ayrıntılarıyla gösterilen, literatürde yer alan ilişki kalitesi boyutları beton sektörünün yetkilileri ile görüşülerek sektörün doğası ve işleyişi göz önünde bulundurularak 6 boyut ve 19 ifade ile ölçülmüştür. İşletmelerin ifadelere ilişkin genel değerlendirmelerini ortaya koymak amaciyla tek örnekli t-testi yapılmıştır (Tablo 3). Buna göre Batıbeton genel olarak, güvenilir, uzun dönemli, güçlü bir iş ilişkisi için gelecek vadeden, iletişim kalitesi yüksek, uyumlu bir iş atmosferi yaratan ve memnuniyet yaratan bir tedarikçi olarak algılanmaktadır. Müşteri sadakatinin de yüksek seviyelerde olduğu, bunun yanı sıra müşterilerinin ilgilendiği ürünler ve söz konusu ürünlerin araç, gereç ile 
ekipmanların beklentilere uygun hazır hale getirilmesi konuları, geliştirilmesi gereken alanlar olarak görülmektedir.

Tablo 3: Katılımcıların Tek Örnekli T-Testi Değerlendirmeleri

\begin{tabular}{|c|c|c|c|c|c|c|}
\hline \multicolumn{5}{|c|}{ Not: Tek örnekli t testi için test değeri=3 (Kararsız) *(1= kesinlikle katılmıyorum } & \multicolumn{2}{|c|}{ 5= kesinlikle kattlyorum) } \\
\hline İFADELER* & Ort. & Std. Sapma. & $\mathrm{t}$ & sd & $\mathrm{p}$ & $\begin{array}{l}\text { Cronbach } \\
\text { Alpha }\end{array}$ \\
\hline \multicolumn{7}{|l|}{ GÜVEN } \\
\hline Güvenilir bir kuruluştur. & 4,59 & 0,668 & 18,599 & 60 & 0,000 & \multirow{4}{*}{0.73} \\
\hline Başarımızla gerçekten ilgilenir. & 4,33 & 0,651 & 15,926 & 60 & 0,000 & \\
\hline Verdiği sözleri yerine getirir. & 4,39 & 0,665 & 16,358 & 60 & 0,000 & \\
\hline İlgilendiğimiz tüm ürünleri her zaman bilir. & 3,84 & 0,986 & 6,621 & 60 & 0,000 & \\
\hline \multicolumn{7}{|l|}{ BAĞLILIK } \\
\hline $\begin{array}{l}\text { Batıbeton ile olan iş ilişkimizin uzun süre } \\
\text { devam edeceğini düşünüyoruz. }\end{array}$ & 4,33 & 0,769 & 13,494 & 60 & 0.000 & \multirow{3}{*}{0.81} \\
\hline Tedarikçimiz olarak Batıbeton'a bağlıyız. & 4,02 & 0,940 & 8,448 & 60 & 0.000 & \\
\hline $\begin{array}{l}\text { Zaman içinde Batıbeton ile olan iş ilişkimizin } \\
\text { güçleneceğine inanıyoruz. }\end{array}$ & 4,46 & 0,647 & 17,602 & 60 & 0.000 & \\
\hline \multicolumn{7}{|l|}{ UYARLAMA } \\
\hline $\begin{array}{l}\text { Batıbeton ürünleri ihtiyacımıza uygun hale } \\
\text { getirir. }\end{array}$ & 3,80 & 0,980 & 6,401 & 60 & 0.000 & \multirow[b]{2}{*}{0.68} \\
\hline $\begin{array}{l}\text { Tüm araç, gereç ve ekipmanları } \\
\text { ihtiyaçlarımıza göre hazır hale getirir. }\end{array}$ & 3,85 & 0,727 & 9,164 & 60 & 0.000 & \\
\hline \multicolumn{7}{|l|}{ İLETİŞIM KALİTESİ } \\
\hline Batıbeton ile kaliteli bir iletişimimiz var. & 4,49 & 0,744 & 15,652 & 60 & 0.000 & \multirow[b]{3}{*}{0.90} \\
\hline Batıbeton ile düzgün bir iletişimimiz var. & 4,48 & 0,622 & 18,719 & 60 & 0.000 & \\
\hline Batıbeton ile eksiksiz bir iletişimimiz var. & 4,47 & 0,595 & 19,580 & 60 & 0.000 & \\
\hline \multicolumn{7}{|l|}{ ATMOSFER } \\
\hline Batıbeton ile uyumlu bir ortamda çalışıyoruz. & 4,34 & 0,772 & 13,598 & 60 & 0.000 & \multirow{3}{*}{0.84} \\
\hline $\begin{array}{l}\text { Batıbeton ile genel olarak ilişkilerimiz } \\
\text { yakındır. }\end{array}$ & 4,36 & 0,633 & 16,780 & 60 & 0.000 & \\
\hline $\begin{array}{l}\text { Projelerde karşılıklı } \\
\text { mevcuttur. }\end{array}$ & 4,34 & 0,602 & 17,430 & 60 & 0.000 & \\
\hline \multicolumn{7}{|l|}{ MEMNUNIYET } \\
\hline İşlerin koordinasyonundan memnunum. & 4,34 & 0,750 & 13,994 & 60 & 0.000 & \multirow{4}{*}{0.79} \\
\hline Bilgi paylaşımı düzeyinden memnunum. & 4,05 & 0,884 & 9,273 & 60 & 0.000 & \\
\hline İşlerin yönetilmesi konusundan memnunum. & 4,38 & 0,662 & 16,236 & 60 & 0.000 & \\
\hline $\begin{array}{l}\text { İşlere olan bağlılık düzeylerinden } \\
\text { memnunum. }\end{array}$ & 4,34 & 0,704 & 14,905 & 60 & 0.000 & \\
\hline \multicolumn{7}{|l|}{ MÜŞTERI SADAKATİ } \\
\hline $\begin{array}{l}\text { Başka şirketlerde çalışan arkadaşlarıma } \\
\text { Batıbeton ile ilgili olumlu şeyler söylerim. }\end{array}$ & 4,41 & 0,739 & 14,903 & 60 & 0.000 & \multirow{4}{*}{0.88} \\
\hline Batıbeton markasını her zaman öneririm. & 4,44 & 0,807 & 13,966 & 60 & 0.000 & \\
\hline $\begin{array}{l}\text { Projelerde Betıbeton ile çalışmaya devam } \\
\text { edeceğiz. }\end{array}$ & 4,30 & 0,955 & 10,595 & 60 & 0.000 & \\
\hline Batıbeton tedarikçi olarak ilk tercihimdir. & 4,46 & 0,697 & 16,349 & 60 & 0.000 & \\
\hline
\end{tabular}

Yukarıda sözü edilen araştırma amaçları doğrultusunda ilişki kalitesi boyutları ile müşteri sadakati değişkenlerinin teorik altyapısı Woo ve Ennew (2004), Huntley (2006), Taulet (2009); Gil-Saura, Frasquet-Deltoro, CerveraTaulet (2009), Cater ve Cater (2010), Mitręga ve Katrichis (2010); Nyaga (2011); Raza ve Rehman (2012) ile Song vd. (2012)'ye dayanmaktadır. Bu doğrultuda 
sadakat bağımlı değişkeninin, güven $\left(\mathrm{r}_{61}=0,618 ; \mathrm{p}<0,05\right)$, uyarlama $\left(\mathrm{r}_{61}=0,517\right.$; $\mathrm{p}<0,05)$, memnuniyet $\left(\mathrm{r}_{61}=0,678 ; \mathrm{p}<0,05\right)$ ile orta, bağl1l1k $\left(\mathrm{r}_{61}=0,842 ; \mathrm{p}<0,05\right)$ ve atmosfer $\left(\mathrm{r}_{61}=0,739 ; \mathrm{p}<0,05\right)$ boyutları ile arasında kuvvetli düzeyde (Gürbüz ve Şahin, 2015:256) anlamlı bir ilişki olduğu görülmektedir.

Araştırma kapsamında ilişki kalitesi boyutlarının müşteri sadakati üzerindeki etkisinin ölçümlenmesi amacıyla aşamalı regresyon (stepwise) analizi yapılmıştır. Aşamalı regresyon analizi, her değişkenin modele sırayla eklendiği, katkısının değerlendirildiği ve katkı sağladığı taktirde modele dahil edilen bir analiz türüdür. Bu analiz türünde, modele katılan diğer tüm değişkenler yeniden test edilerek katkı sağlayıp sağlamamalarına göre modele dahil edilir ya da modelden çıkarılmaktadır (Öztürk, 2005:260). Regresyon analizinin sonuçları Tablo 4'te gösterilmektedir. Buna göre aşamalı regresyon analizi, ilişki kalitesi boyutlarından sadece bağl1lık ile atmosfer değişkenlerini 2 aşamalı model çerçevesinde anlamlı bulmuş, diğer değişkenleri model dişında bırakmıştır. Tablo 4 'ten de görülebileceği gibi bağl1lık değişkeni müşteri sadakatine olan etkisinde bileşik korelasyon katsayısı 0,842 iken, ikinci aşamada bu değer 0,859 'a yükselmiştir. İlgili $\mathrm{R}^{2}$ değerlerine göre atmosfer değişkeni ikinci aşamada modele katılmasıyla açılanan toplam varyans yüzde 73,9'a yükselmiştir $(\mathrm{F}=81,902 ; \mathrm{p}<0,05)$.

Tablo 4: İlişki Kalitesi Boyutları ile Müşteri Sadakati Arasındaki Aşamalı Regresyon Analizi Sonuçları

\begin{tabular}{|l|l|l|l|l|l|l|}
\hline & $\begin{array}{l}\text { Bağımsız } \\
\text { Değişkenler }\end{array}$ & $\mathrm{R}$ & $\mathrm{R}^{2}$ & $\mathrm{R}^{2}$ deki Değişim & Std.Hata & $\mathrm{F}$ \\
\hline 1.Model & Bağll1ık & 0,842 & 0,708 & 0,703 & 0,37323 & $143,149^{*}$ \\
\hline & $\begin{array}{l}\text { Bağgl1lık } \\
\text { Atmosfer }\end{array}$ & 0,859 & 0,739 & 0,729 & 0,35631 & $81,902^{*}$ \\
\hline
\end{tabular}

Aşamalı regresyon analizi sonuçlarına göre güven, uyarlama ve memnuniyet değiş̧kenlerinin bağımlı değişken üzerinde herhangi anlamlı bir etkisi olmaması nedeniyle model dışı bırakılmıştır. Aşamalı regresyon sadece bağlılık ve atmosfer değişkenini modele dahil etmiştir. $\mathrm{Bu}$ doğrultuda araştırmanın $\mathrm{H}_{2}$ ve $\mathrm{H}_{4}$ hipotezleri kabul edilmiş olup, $\mathrm{H}_{1}, \mathrm{H}_{3}$, ve $\mathrm{H}_{5}$ hipotezleri reddedilmiştir.

İletişim kalitesi, bağll1ık değişkeninin müşteri sadakati $\left(\mathrm{r}_{58}=0,647 ; \mathrm{p}=0,00\right)$ üzerindeki etkisinde kısmi moderatör (Sharma, Durand ve Gur-Arie, 1981:297) olarak değerlendirilmektedir. Buna göre iletişim kalitesi, ilişkiye olan bağl1lığın müşteri sadakati üzerindeki gücünü zayıflatmaktadır. Diğer bir ifadeyle, Batıbeton grubunun müşterileriyle halihazırda sürdürdüğü iletişimin, bu ilişkiye olan bağl1lığın sadakat üzerindeki etkisini azaltmakta olup bu anlamda müşterilerle geliştirilmesi gereken bir iletişim yapısının gerekliliği göz önünde bulundurulmalıdır. İletişim kalitesi ve bağlılık değişkeni etkileşim teriminin beta katsayıs1 0,336 ( $\mathrm{t}=2,299 ; \mathrm{p}=0,025)^{\prime}$ dır. Ayrıca iletişim kalitesi, yaratılan ilişki atmosferinin müşteri sadakati $\left(\mathrm{r}_{58}=0,398 ; \mathrm{p}=0,00\right)$ üzerindeki etkisinde de kısmi moderatör (Sharma, Durand ve Gur-Arie, 1981:297) olarak değerlendirilmektedir. Dolayısıyla, iletişim kalitesi atmosferin müşteri sadakati üzerindeki etkisinde 
0,341'lik bir düşüşe neden olmuştur. İletişim kalitesi arttırıldıkça daha uyumlu bir atmosfer yaratılarak müşteri sadakati arttırılabilecektir. Bu bulgulara yönelik olarak gelecekte daha farklı analizler yapılmalıdır. İletişim kalitesi ve atmosfer değişkeni etkileşim teriminin beta katsayısı $0,456(\mathrm{t}=2,158 ; \mathrm{p}=0,035)$ 'dir.

Elde edilen bulgular Athanasopoulou, (2009), Woo ve Ennew (2004), Leonidou vd. (2006), Cater ve Cater (2010), Nyaga (2011), Moliner vd.(2013), Madupalli vd.(2014)'nin çalışmalarında ilişkide güvenin; Su, vd. (2008) ile Song (2012)'nin çalışmalarında endüstriyel pazarlarda yaratılan olumlu ve uyumlu atmosfer algısının ilişkinin kalitesini arttıracağı ve oluşan başarılı ilişki yapısının müşteri sadakatini arttıracağına ilişkin bulguları desteklemektedir.

\section{SONUÇ}

Son yıllarda özellikle büyük konut projeleri kaynaklı konut talebinin artmas1, kentsel dönüşüm projesi nedeniyle hazır betona olan ihtiyacın ve tesis sayısının artması gibi nedenlerle (Akakın vd.,2013:70) sektördeki işletme sayıs1 günden güne artmış ve hazır beton sektörü yoğun bir rekabetin yaşandığı dinamik bir sektör haline gelmiştir. Geçmişte hazır beton sektöründe pazarlama faaliyetleri daha çok fiyat ve satış odaklı olmakla birlikte, yukarıda sözü edilen gelişmeler ve rekabetin gün geçtikçe artması gibi nedenlerle uygulanan satış odaklı yaklaşımlar rekabet avantajı yaratmak anlamında oldukça yetersiz kalmıştır. Sektördeki rekabet, yeni müşteriler bulmanın yanı sıra, mevcut müşterileri sadık birer müşteri haline getirme zorunluluğunu da beraberinde getirmiştir. Müşteri sadakati, ancak daha müş̧eri odaklı, uzun dönemli ilişkilerde kaliteye önem veren bir politika ve strateji ile mümkün olabilmektedir.

Batıbeton Beton San. A.Ş’nin müşterilerine yönelik olarak gerçekleştirilen ve tanımlayıcı bir araştırma niteliğinde olan bu çalışmada, Batıbeton'un müşterileri ile oluşturduğu ilişki kalitesi, literatürden elde edilen ve daha sonra hazır beton sektörüne uyarlanarak elde edilen güven, bağlllık, uyarlama, atmosfer ve memnuniyet boyutları itibariyle değerlendirilmiştir. Müşterilerinin genel olarak Batbeton'a yönelik sadık olduğu, ancak müşterilerinin ilgilendiği ürünler ve söz konusu ürünlerin araç, gereç ile ekipmanların beklentilere uygun, hazır hale getirilmesi konularında daha çok dikkat edilmesi gerekliliği ortaya çıkmıştır. Yapılan analizler neticesinde, Batıbeton bağlılık ve atmosfer boyutlarının, müşterilerin sadık birer müşteri haline gelmelerini etkileyen en önemli değişkenler olduğu görülmektedir. Dolayısıyla, müşterilerin ilişkiye olan bağl1lıklarının artması ve müşterilerinin Batıbeton ile ilişkilerini uyumlu ve yakın olarak algılamaları arttıkça, müşteri sadakati daha da artacaktır. Çalışmanın en önemli kısıtını oluşturan, anket cevaplamaya vakit ayrılmasının istenmemesi ve isteksizlik gibi konuların aşılması ve anket sayısının artması durumunda daha farklı boyutlar da etkili olabilecektir. Elde edilen bulgular Athanasopoulou, (2009), Woo ve Ennew (2004), Leonidou vd. (2006), Cater ve Cater (2010), Nyaga (2011), Moliner vd.(2013), Madupalli vd.(2014)'nin çalışmalarında ilişkide güvenin; Su, vd. (2008) ile Song (2012)'nin çalışmalarında endüstriyel pazarlarda yaratılan olumlu ve 
uyumlu atmosfer algısının ilişkinin kalitesini arttıracağı ve oluşan başarılı ilişki yapısının müşteri sadakatini arttıracağına ilişkin bulguları desteklemektedir.

Diğer önemli bir bulgu ise iletişim kalitesinin bağl1lık ve atmosfer değişkenlerinin müşteri sadakati üzerindeki etkisinde kısmi moderatör olarak değerlendirilmiş olmasıdır. Müşterilerle olan mevcut iletişim düzeyi hem bağlılık değişkeninin hem de atmosfer değişkeninin müşteri sadakati üzerindeki etkisini güçsüzleştirmektedir. Dolayısıyla gelecekte bu duruma yönelik daha ileri analizlerin yapılması faydalı olacaktır.

Çalışmanın ilişki boyutlarının ortaya konması ve müşteri sadakati yaratma yolunda ilişki kalitesinin önemini vurgulaması anlamında endüstriyel işletmelere 1şık tutması beklenmektedir. Bu çalışmanın, literatürdeki farklı ilişki kalitesi boyutlarının dahil edilmesi ve daha geniş kapsamlı bir örneklem büyüklüğü ile gerek hazır beton sektöründe gerekse diğer sektörlerde yapılacak araştırmalara altyapı sağlayacağı düşünülmektedir.

\section{KAYNAKÇA}

Akakın, T., Kılınç C., Işık A., Zengin H. (2013). Hazır Beton Sektörü ve Beton Kullanımındaki Gelişmeler. Hazır Beton, 66-72, http://www.thbb.org/media/2088/makalethbb116.pdf

Arslan, M. (2012). Endüstriyel Pazarlama. İstanbul: Beta.

Athanasopoulou, P. (2006). Determining Relationship Quality in The Development of Business-toBusiness Financial Services. Journal of Business-to-Business Marketing, 13(1), 87-120. doi:10.1300/J033v13n01_03

Aydin, S., Ozer, G. (2005). Customer Loyalty and the Effect of Switching Costs As a Moderator Variable. Marketing Intelligence and Planning, 23(1), 89-103. doi: http://dx.doi.org/10.1108/02634500510577492

Ata, U. Z., Toker A. (2012). The Effect of Customer Relationship Management Adoption in Businessto-Business Markets. Journal of Business \& Industrial Marketing, 27(6), 497 - 507. doi: http://dx.doi.org/10.1108/08858621211251497

Boonlertvanich, K. (2011), Effect of Customer Perceived Value on Satisfaction and Customer Loyalty in Banking Service: The Moderating effect of Main-Bank Status. International Journal of Business Research, 7(6), 40-54

Bowen, J.T, Shoemaker, S. (2003). Loyalty: A Strategic Commitment. Cornell Hospitality Quarterly, 44(Qctober), 31-46. doi:10.1016/S0010-8804(97)83878-5

Brennan, R., Turnbull, P. W. (1999). Adaptive Behavior in Buyer-Supplier Relationships. Industrial Marketing Management, 28(5), pp. 481-495. doi: http://dx.doi.org/10.1016/S00198501(99)00057-7

Čater T, Čater B. (2010). Product and Relationship Quality Influence on Customer Commitment and Loyalty in B2B Manufacturing Relationships, Industrial Marketing Management 39, 13211333. doi: http://dx.doi.org/10.1016/j.indmarman.2010.02.006

Chang, Y., Chen, F. (2007). Relational Benefits, Switching Barriers and Loyalty: A Study of Airline Customers in Taiwan. Journal of Air Transport Management, 13(2), 104-109. doi: http://dx.doi.org/10.1016/j.jairtraman.2006.10.001

Eriksson K, Vaghult LA. (2000). Customer Retention, Purchasing Behavior and Relationship Substance in Professional Services. Industrial Marketing Management, 29, 363-372. doi: 10.1016/S0019-8501(00)00113-9

Ford, D., Ha ${ }^{\circ}$ kansson, H. (2006). IMP - Some Things Achieved: Much More To Do. European Journal of Marketing, 40(3/4), 248-58. doi: http://dx.doi.org/10.1108/03090560610648039

Fornell, C. (1992). A National Customer Satisfaction Barometer: The Swedish Experience. Journal of Marketing, 56(1), 6-21. http://www.jstor.org/stable/1252129

Ganesan, S. (1994). Determinants of Long-Term Orientation in Buyer-Seller Relationships. Journal of Marketing, 58(1), 1-19. http://www.jstor.org/stable/1252265 
Gounaris, Spiros P. (2005). Trust and Commitment Influences on Customer Retention: Insights From Business-To-Business Services, Journal of Business Research, 58, 126- 140. doi: 10.1016/S0148-2963(03)00122-X

Griffin, J. (1996). The Internet's Expanding Role in Building Customer Loyalty. Direct Marketing, 59(7), 50-53

Guenzi, P., Pardo, C., Georges, L. (2007). Relational Selling Strategy and Key Account Managers' Relational Behaviors: An Exploratory Study. Industrial Marketing Management, 36, 121133. DOI: http://dx.doi.org/10.1016/j.indmarman.2005.03.014

Gümmesson, E. (2002). Relationship Marketing in the New Economy. Journal of Relationship, 1(1), 37-57. doi: http://dx.doi.org/10.1108/08876040210447315

Gürbüz S., Şahin F. (2015). Sosyal Bilimlerde Araştırma Yöntemleri (2. Baskl). Ankara: Seçkin.

Hennig-Thurau, T., Gwinner, K. P., Gremler, D. D. (2002). Understanding Relationship Marketing Outcomes: An Integration of Relational Benefits and Relational Quality. Journal of Service Research, 4(3), 230-247. doi: 10.1177/1094670502004003006

Holmlund, M. (2008). A Definition, Model, and Empirical Analysis of Business-to-business Relationship Quality, International Journal of Service Industry Management,19(1), 32-62. doi: http://dx.doi.org/10.1108/09564230810855707

Hunt, S.D., Arnett, D.B., Madhavaram, S. (2006). The explanatory foundations of relationship marketing theory. Journal of Business and Industrial Marketing, 21(2), 72-87. doi: $10.1108 / 10610420610651296$

Huntley, J.K. (2006). Conceptualization and Measurement of Relationship Quality: Linking Relationship Quality to Actual Sales and Recommendation Intention. Industrial Marketing Management 35, 703 - 714. doi: http://dx.doi.org/10.1016/j.indmarman.2005.05.011

Irene G., Frasquet-Deltoro, M., Cervera-Taulet A. (2009). The Value of B2B Relationships. Industrial Management \& Data Systems, 109(5), 593 - 609. doi: http://dx.doi.org/10.1108/02635570910957605

Kumar V., Shahb, D. (2004). Building and Sustaining Profitable Customer Loyalty for the 21st Century. Journal of Retailing, 80, 317-330. doi: http://dx.doi.org/10.1016/j.jretai.2004.10.007

Leonidou, L. C., Barnes, B. R., Talias, M. A. (2006). Exporter Importer Relationship Quality: The Inhibiting Role of Uncertainty, Distance, and Conflict. Industrial Marketing Management, 35, 576-588. doi: http://dx.doi.org/10.1016/j.indmarman.2005.06.012

Leuthesser, L. (1997). Supplier Relational Behaviour: An Empirical Assessment, Industrial Marketing Management, 26(3), 245-54. doi: 10.1016/S0019-8501(96)00092-2

Leverin, A., Liljander, V. (2006). Does Relationship Marketing Improve Customer Relationship Satisfaction and Loyalty. International Journal of Bank Marketing, 24(4), 232-251. doi: http://dx.doi.org/10.1108/02652320610671333

Lin, C.P., Ding, C.G. (2006). Evaluating Group Differences in Gender During The Formation o Relationship Quality and Loyalty in ISP Service. Journal of Organizational and End User Computing, 18(2), 38-62. doi: 10.4018/978-1-59904-295-4.ch014

Liu, Y., Li, Y., Zhang, L. (2010). Control Mechanisms Across A Buyer-Supplier Relationship Quality Matrix.Journal of Business Research 63, 3-12. doi: http://dx.doi.org/10.1016/j.jbusres.2009.01.005

Madupalli R., Pannirselvam G., Williams C. (2014). Quality of Business to Business Relationships: Impact of Customer-Supplier Differences, Academy of Marketing Studies Journal, 18(2), 149-160.

Mitręga M., Katrichis J. (2010). Benefiting from Dedication and Constraint in Buyer-Seller Relationships, Industrial Marketing Management, 39, 616-624. doi: http://dx.doi.org/10.1016/j.indmarman.2009.05.004

Mohr, J., Spekman, R., (1994). Characteristics of Partnership Success: Partnership Attributes, Communication Behavior and Conflict Resolution Techniques. Strategic Management Journal, 15, 135-152. doi: 10.1002/smj.4250150205 
Moliner, J. S., Moliner M., Sánchez-Garcia T. J. (2013). Relationship Quality in Business To Business: A Cross-Cultural Perspective From Universities. Marketing Intelligence \&Planning, 31(3), 196 - 215. doi: http://dx.doi.org/10.1108/02634501311324573

Morgan RM, Hunt SD, (1994). The Commitment-Trust Theory of Relationship Marketing. Journal of Marketing 58, 20-38. doi: 10.2307/1252308

Nyaga, G. N., Whipple J. M.(2011). Relationship Quality and Performance Outcomes: Achieving a Sustainable Competitive Advantage. Journal of Business Logistics, 32(4), 345-360. doi: 10.1111/j.0000-0000.2011.01030.x

ÖZTÜRK, E. (2005). Çoklu Doğrusal Regresyon Modeli, SPSS Uygulamalı Çok Değiş̧kenli İstatistik Teknikleri. Şeref Kalaycı (Ed.). Ankara: Asil.

Panayides, P. M. (2002). Identification of Strategic Groups Using Relationship Marketing Criteria: A Cluster Analytic Approach in Professional Services. The Service Industries Journal, 22(2), 149-166. doi: 10.1080/714005071

Peng LY, Wang Q. (2006). Impact of Relationship Marketing Tactics (RMTs) on Switchers and Stayers in a Competitive Service Industry. Journal of Marketing Management, 22, 25-59. doi: 10.1362/026725706776022263

Raza, A., Rehman Z. (2012). Impact of Relationship Marketing Tactics on Relationship Quality and Customer Loyalty: A Case Study of Telecom Sector of Pakistan. African Journal of Business Management, 6(14), 5085-5092. doi: 10.5897/AJBM11.3022

Rauyruen, P., Miller, K. E. (2007). Relationship Quality As a Predictor of B2B Customer Loyalty. Journal of Business Research, 60, 21-31. doi: http://dx.doi.org/10.1016/j.jbusres.2005.11.006

Roberts, K., Varki, S. and Brodie, R. (2003). Measuring The Quality of Relationships in Consumer Services: An Empirical Study. European Journal of Marketing, 13(1/2), 169-196. doi: http://dx.doi.org/10.1108/03090560310454037

Russo, I., Confente I., Gligor D.M. and Autry C.W. (2015). To Be Or Not To Be (Loyal): Is There a Recipe For Customer Loyalty in The B2B Context?. Journal of Business Research, 1-19. doi: http://dx.doi.org/10.1016/j.jbusres.2015.07.002

Sahay, B.S. (2003). Understanding Trust in Supply Chain Relationship. Industrial Management \& Data Systems, 103(8), 553-563. doi: http://dx.doi.org/10.1108/02635570310497602

Sharma S., Durand R., Oded Gur-Arie. (1981). Identification and Analysis of Moderator Variables. Journal of Marketing Research, 18, 291-300, http://www.jstor.org/stable/3150970

Sindhav, B.G., Lusch, R.F. (2008). An Identification-Based Model of Supplier-Retailer Communication. Journal of Marketing Channels, 15(4), 281-314. doi: 10.1080/10466690802063978

Spreng, R. A., MacKenzie S. B., Olshavsky R.W. (1996). A Reexaminaition of the Determinants of Consumer Satisfaction, Journal of Marketing, 60, pp.15-32, http://www.jstor.org/stable/1251839

Su, Q., Song, Y., Li, Z., Dang, J. (2008). The Impact of Supply Chain Relationship Quality on Cooperative Strategy. Journal of Purchasing \& Supply Management, 14, 263-272. doi: http://dx.doi.org/10.1016/j.pursup.2008.08.002

Svensson, G. (2004). Vulnerability in Business Relationships: The Gap Between Dependence and Trust. Journal of Business \& Industrial Marketing, 19(7), 469-483. doi: http://dx.doi.org/10.1108/08858620410564418

THBB (Türkiye Hazır Beton Birliği). (2015), 2013 - 2014 Yı1ı Hazır Beton Sektörü İstatistikleri, THBB Yayılar1 http://www.thbb.org/media/74449/2013-2014-hazır-beton-sektoruverileri22062015.pdf [15.01.2016]

Ulaga, W. (2003), Capturing Value Creation in Business Relationships: A Customer Perspective, Industrial Marketing Management, 32(8), pp.677-693. doi: http://dx.doi.org/10.1016/j.indmarman.2003.06.008

Veloutsou, C, Daskou, S., Daskou, A. (2004). Are the Determinants of Bank Loyalty Brand Specific?. Journal of Financial Services Marketing, 9(2), 113-125. doi:10.1057/palgrave.fsm.4770146 
Woo, K. S., Ennew, C. T. (2004). Business-to-Business Relationship Quality: An IMP InteractionBased Conceptualization and Measurement, European Journal of Marketing, 38(9/10), 1252-1271. doi: http://dx.doi.org/10.1108/03090560410548960

Song, Y., Su, Q., Liu, Q., and Wang, T. (2012). Impact of Business Relationship Functions on Relationship Quality and Buyer's Performance. Journal of Business \& Industrial Marketing, 27(4), 286-298. doi: http://dx.doi.org/10.1108/08858621211221661

\section{SUMMARY}

Before the year 2000, in ready-mix concrete industry, the formation of marketing philosophy is hindered due to the lack of businesses which are not capable of meeting the demand created by customers. Also the increase in number of businesses in the industry could not keep pace with the skyrocketing demand of ready-mix concrete, so the businesses in the industry continued their activities with production focused policies and strategies. After the year 2000, with the increase in number of businesses entering the industry, market dynamics have changed, besides using the pricing policies as a tool for competition in order to keep up with the change and improvements, businesses have to follow customer based policies intended to improve long term relationship quality. Ready-mix concrete industry had been developed and the relevant standards of the industry had already established, construction inspection system is also being settled with the acceleration in the construction industry which can be named as one of the most important sectors leading our economy. With these dynamics established, number of businesses within the industry had increased seriously. In the ready-mix concrete industry, in which the competition is highly intensive, service quality, customer relationship and even the efforts for bringing the quality perception regarding the customer relationship at the top, has became the most important elements that are creating the competitive advantage. Thus, gaining loyal customers depending on the long term and strong relationships had become the most essential goal of the businesses. In this scope, the aim of the study is to measure the effect of relationship quality on customer loyalty. In this framework, the study was designed as a descriptive research and a questionnaire was applied to the customers of Batibeton Beton San. A.Ş. The dimensions of commitment and atmosphere among the other dimensions of relationship quality, are found to be the most important dimensions increasing the customer loyalty, whereas communication level is evaluated as partial moderator. In this scope, in the first phase relationship quality and its dimensions are investigated in industrial markets, then a literature survey is carried out regarding to customer loyalty and relationship quality dimensions' effects on customer loyalty. Lastly, findings of the field work are given. Relationship quality is more important in the industrial markets with similar quality. There are a variety of relationships both in consumer and in industrial markets. The perception of a high quality relationship between/among parties paves the way for customer satisfaction, loyalty, positive word of mouth communication, and sustainable business relationships among parties. Perception of high quality relationship will boost the commitment of parties to the relationship, and motivate them for making 
contributions for it. Relationship quality is covered with the dimensions of trust, commitment, adaptation, atmosphere and satisfaction since the study is directed at industrial businesses and because of the nature of relationships between parties and business in ready-mix concrete industry.

As a result of the analyses, it is seen that the Batibeton commitment and atmosphere dimensions are the most important variables affecting company's customers to be loyal. So customer loyalty will increase as the customers' commitment to the relationship and the level at which the customers perceive their relationship with Batıbeton as coherent and close increase. The most important limitation of the study is people's unwillingness to allocate some time for answering the questionnaire and reluctance. If these limitations are overcame, the number of questionnaires answered will increase and different dimensions can be effective. The other important finding is that the communication quality is evaluated as a partial moderator for the relationship between the variables of commitment and atmosphere. Current communication level with the customers weaken both the commitment's and atmosphere's effect on customer loyalty. So it will be useful to carry out detailed analyses addressing this situation in future.

The study is expected to shed a light to industrial businesses for revealing the relationship dimensions and emphasizing the importance of relationship quality on the way to create customer loyalty. 